Published in final edited form as:

Eur Urol Focus. 2017 February ; 3(1): 119-129. doi:10.1016/j.euf.2016.02.001.

\title{
Phosphodiesterase-5 inhibitors for premature ejaculation: a systematic review and meta-analysis
}

\author{
Dr Marrissa Martyn-St James ${ }^{1}$, Dr Katy Cooper $^{1}$, Dr Shijie Ren ${ }^{1}$, Dr Eva Kaltenthaler ${ }^{1}$, Ms K \\ Dickinson ${ }^{1}$, Ms A Cantrell ${ }^{1}$, Prof Kevan Wylie ${ }^{2}$, Dr Leila Frodsham ${ }^{3}$, and Dr Catherine \\ Hood $^{4}$ \\ ${ }^{1}$ School for Health and Related Research (ScHARR), University of Sheffield, Regent Court, 30 \\ Regent Street, Sheffield, S1 4DA \\ ${ }^{2}$ Porterbrook Clinic, Sexual Medicine, Sheffield \\ ${ }^{3}$ Institute of Psychosexual Medicine, London \\ ${ }^{4}$ St George's Hospital, London
}

\begin{abstract}
Context-Phosphodiesterase-5 inhibitors (PDE5is) are prescribed off-label for the treatment of premature ejaculation (PE).
\end{abstract}

Objective-To systematically review the evidence from randomised controlled trials (RCTs) for PDE5is in the management of PE.

Evidence acquisition-MEDLINE and other databases were searched to September 2015. Quality of RCTs was assessed. Intra-vaginal ejaculatory latency time (IELT) data were pooled in a meta-analysis. Heterogeneity was assessed.

Evidence synthesis-Fifteen RCTs were included. The majority were of unclear methodological quality. Pooled IELT evidence suggests: PDE5is are significantly more effective than placebo (231 participants, $\mathrm{p}<0.00001$ ); there is no difference between PDE5is and selective serotonin reuptake inhibitors (SSRIs) (405 participants, $\mathrm{p}=0.50$ ); and that PDE5is combined with an SSRI are significantly more effective than SSRIs alone (521 participants, $\mathrm{p}=0.001$ ). However, high levels of statistical heterogeneity are evident $\left(\mathrm{I}^{2} \geq 40 \%\right)$. Single RCT evidence suggests that sildenafil is significantly more effective than the squeeze technique; but both lidocaine gel and tramadol are significantly more effective than sildenafil. Sildenafil combined with behavioural therapy is significantly more effective than behavioural therapy alone. Sexual satisfaction and ejaculatory control appear better with PDE5is compared with placebo and with PDE5is combined with an SSRI compared with an SSRI alone. Adverse events are reported with both PDE5is and other agents.

Conclusions-PDE5is are significantly more effective than placebo and PDE5is combined with an SSRI are significantly more effective than SSRIs alone at increasing IELT and improvement in 
other effectiveness outcomes. However, heterogeneity is evident across RCTs. The methodological quality of the majority of RCTs is unclear.

Patient summary-We reviewed PDE5is for treating premature ejaculation. We found evidence to suggest that PDE5is are effective compared with placebo and that PDE5is combined with an SSRI are better than an SSRI alone. Adverse events are reported with PDE5is and other agents. However, the quality of the evidence is uncertain.

PROSPERO registration number: CRD42013005289

\section{Introduction}

Premature ejaculation (PE) is commonly defined by a short ejaculatory latency, a perceived lack of ejaculatory control; both related to self-efficacy; and distress and interpersonal difficulty [1]. PE can be either lifelong (primary - present since first sexual experiences), or acquired (secondary - beginning later) [2]. The International Society of Sexual Medicine's Ad Hoc Committee for the Definition of Premature Ejaculation defines PE as a male sexual dysfunction characterised by ejaculation within about one minute of vaginal penetration (lifelong PE) or a clinically significant and bothersome reduction in latency time to $\measuredangle$ minutes (secondary PE), the inability to delay ejaculation, and negative personal consequences[3].

The treatment of PE should attempt to alleviate concern about the condition as well as increase sexual satisfaction for the patient and the partner [4]. Available treatment pathways for the condition are varied and treatments may include both behavioural and/or pharmacological interventions. Phosphodiesterase-5 (PDE5) inhibitors are prescribed for the condition off-label. A number of randomised controlled trials (RCTs) and observational studies have compared PDE5 inhibitors (PDE5is) with placebo, no therapy, behavioural therapy or pharmacological agents. Previous reviews have summarised this evidence [5-9]. However, none to-date has presented a meta-analysis of only RCT evidence.

The aim of this study was to systematically review the evidence for PDE5is, in the treatment of PE, by summarising evidence from RCTs and present a meta-analysis of treatment effectiveness.

\section{Evidence acquisition}

The review was undertaken in accordance with the general principles recommended in the Preferred Reporting Items for Systematic Reviews and Meta-Analyses (PRISMA) statement. 11

\subsection{Searches}

MEDLINE and other bibliographic databases were searched from inception to 30 September 2015Details of all sources searched and full search terms are reported elsewhere [10]. All citations were imported into Reference Manager Software (version 12, Thomson ResearchSoft, Carlsbad, CA, USA) and any duplicates deleted. 


\subsection{Eligible studies}

RCTs in adult men with PE that evaluated a PDE5i alone or in combination with another therapy were eligible for inclusion. Single-arm randomised crossover design studies (participants randomised to different intervention periods) were excluded to avoid double counting of participants in the meta-analysis. Theses and dissertations were not included. Non-English publications were included where sufficient data could be extracted from an English-language abstract or tables.

The primary outcome was intra-vaginal ejaculatory latency time (IELT). Other outcomes included sexual satisfaction, control over ejaculation, relationship satisfaction, self-esteem, quality of life, treatment acceptability and adverse events.

\subsection{Data extraction, quality assessment and data synthesis}

One reviewer performed data extraction of each included study. All numerical data were then checked by a second reviewer.

Methodological quality of RCTs was assessed using the Cochrane Collaboration risk of bias assessment criteria [11]. We classified RCTs as being at overall 'low' or 'high' risk of bias if they were rated as such for all three of the following key domains - (i) allocation concealment; (ii) blinding of outcome assessment; and (iii) completeness of outcome data (attrition <30\%).

Where possible, between-group differences were pooled across RCTs in a meta-analysis using Cochrane RevMan software (version 5.2) (RevMan 2012[12]). Random-effects models were applied where $P$ value was $>40 \%$. Between-group effect estimates were considered significant at $\mathrm{p}<0.05$. Assessment of publication bias assessed by visual inspection of funnel plots was planned where $\geq 10 \mathrm{RCT}$ comparisons were available.

\section{Evidence synthesis}

\subsection{Search results}

The searches identified 2,391 citations. Of these, 2,369 citations were excluded as titles/ abstracts. Twenty-two full-text articles were obtained as potentially relevant. The study selection process is fully detailed in the PRISMA flow diagram in Supplementary Figure 1. A total of 15 RCTs that evaluated a PDE5i (with or without a combined therapy) against a comparator were included.

Details of the included RCTs are presented in Table 1.

\subsection{Risk of bias assessment of RCTs}

The majority of RCTs were considered at unclear risk of bias mainly due to lack of reporting of information to inform the risk of bias assessment. Four RCTs were described as singleblind or open-label and were considered at high risk of performance bias.[14-17] One RCT was considered at high risk of selective reporting as although IELT and secondary outcomes were assessed, IELT outcomes were not reported and secondary outcomes minimally reported (no data)[14]. One RCT was considered to be at overall high risk of bias as group 
allocation sequence was according to patients' presentation at clinic[17]. One RCT was considered to be at overall high risk of bias as numbers withdrawing at six months were imbalanced, with $>30 \%$ in one group and no indication whether these participants were included in the analysis or otherwise[16]. We were unable to assess fully two RCTs fully as the body text was in Chinese-language, which were judged at overall unclear risk [18;19]. Only one RCT was judged at overall low risk of bias [20]. A summary of the risk of bias assessment for each included RCT is presented in Supplementary Figure 2.

\subsection{Characteristic of RCTs}

Where reported, the definition of PE was varied and was defined according to: DSM-IV (Diagnostic and Statistical Manual of Mental Disorders) criteria[20-23], an IELT of two minutes or less [16;19;23;24], 1.5 minutes or less [22], or 1 minute or less [25;26]; a score of four or less on the CMASH (Center for Marital and Sexual Health questionnaire)[15], or was not reported $[6 ; 14 ; 18 ; 19 ; 27]$. The majority of RCTs recruited samples comprising men with lifelong PE and without erectile dysfunction. One RCT recruited men with both lifelong and acquired PE[19] and one RCT recruited only me with acquired PE.[17] The remaining RCTs recruited samples comprising men with lifelong PE. Where reported, men with erectile dysfunction (ED) were excluded. Where reported, ED was assessed by the majority of trials using the International Index of Erectile Function (IIEF). IIEF ED cut-off scores for exclusion ranged from $<21$ to $<26$.

The majority of RCTs evaluated sildenafil. [16-19;21;23-25] Other PDE5is included tadalafil,[14;22;26;27] mirodenafil[20] and vardenafil[15;28]. With the exception of one RCT prescribing tadalafil twice weekly[14], all RCTs prescribed PDE5is prior to sexual intercourse. Comparators included placebo, selective serotonin re-uptake inhibitors (SSRIs), tramadol, behavioural therapy, and anaesthetic gels or creams. With the exception of three RCTs prescribing an SSRI daily[14;16;17;26] or weekly[22]; and one RCT prescribing a daily SSRI for four weeks followed initially followed by administration on demand prior to sexual intercourse to week 16[25]; SSRIs were prescribed to be taken prior to sexual intercourse, including one RCT prescribing dapoxetine (approved administration on-demand for the treatment of PE[29]) [20]. Five RCTs evaluated combination therapies comprising PDE5is combined with an SSRI.[14;17;20;22;25] Treatment duration ranged from four weeks to six months. Where reported, trials were undertaken in both EU and non-EU countries.

\subsection{Outcome data reported in RCTs}

With the exception of one RCT reporting 'improvement' or 'cure'[21], all RCTs reported IELT outcomes as a time metric. One RCT assessed IELT using a visual scale of ejaculatory latency time questionnaire, although no outcome data were reported[14]. Two RCTs reported that IELT was estimated by patients without using a stopwatch.[17;27] The remaining RCTs reported that IELT was assessed using a stopwatch.

The reporting of other efficacy outcomes was varied, both in the assessment method (Table 1) and the outcome data available (Supplementary Table). The outcome data for adverse event (AE) reporting was similarly disparate in terms of the types of adverse events and 
whether the proportion was the number of patients or the number of AEs (Table 2,

Supplementary Table).

\subsection{IELT outcomes}

A results summary of the effectiveness outcomes and adverse events is presented in Table 2.

IELT - PDE5is vs. placebo: The pooled effect estimate across three RCTs[22-24] (231 participants) ( $\mathrm{I}^{2}=42 \%$, random-effects) was 2.21 minutes (95\% CI 1.45 to $2.97 ; \mathrm{p}<0.00001$ ) in favour of PDE5is (Figure 1, Table 2). The between-group difference in geometric mean increase in IELT from one additional RCT [28] (40 participants) was 3.60 minutes in favour of vardenafil compared with placebo [MD (fixed effect) $95 \%$ CI, 3.10 to 4.10 ; $p<0.00001$ ].

IELT - PDE5is vs. SSRIs: Pooled effects across six RCTs[15;16;18;22;24;27] (405 participants) for PDE5is compared with SSRIs display high levels of between-trial heterogeneity $\left(\mathrm{I}^{2}=95 \%\right)$. The pooled between-group difference in IELT was 0.33 minutes (random-effects; 95\%CI, -0.63 to $1.30 ; \mathrm{p}=0.50$ ) (Figure 2, Table 2).

IELT - PDE5is plus SSRIs vs. SSRIs: Pooled effects across six RCTs[17;19;20;22;25;27] (521 participants) for PDE5is plus SSRI combination therapy compared with SSRIs alone display high levels of between-trial heterogeneity $\left(\mathrm{I}^{2}=75 \%\right)$. The pooled between-group differences in IELT was 1.52 minutes (random-effects; 95\%CI, 0.98 to 2.05; $\mathrm{p}<0.00001$ ) in favour of PDE5i/SSRI combination therapy (Figure 3, Table 2). One further RCT reported a between-group difference in change in IELT at 6 weeks of 1.02 minutes in favour of tadalafil plus sertraline compared sertraline plus placebo. [26] Variance estimates were not reported. The authors reported a $p$-value for the between-group difference of $\mathrm{p}=0.001$.

IELT - PDE5is vs. squeeze technique, lidocaine gel or tramadol: Sildenafil was significantly more effective than the squeeze technique (one RCT, 120 participants [16]) at increasing IELT (MD 3.56 minutes [95\% CI 3.16 to 3.96; p <0.00001]) (Figure 4, Table 2). Both lidocaine gel and tramadol (one RCT, [24] 60 and 59 participants respectively) were significantly more effective than sildenafil at four weeks (MD 0.83 minutes [95\% CI 0.05 to 1.61; $\mathrm{p}=0.04$ ]; and 2.04 minutes [95\% CI 1.21 to 2.87], $\mathrm{p}<0.00001$ respectively) (Figure 4).

IELT - PDE5is plus behavioural therapy vs. behavioural therapy: Sildenafil combined with behavioural therapy (not described) was significantly more effective than behavioural therapy alone (one RCT, 60 participants [18]) at increasing IELT (MD 3.56 minutes 1.81 minutes [95\% CI 1.53 to 2.09], $\mathrm{p}<0.00001$ ) (figure not presented).

\subsection{Outcomes other than IELT}

The assessment and reporting of outcomes other than IELT was diverse across RCTs (Supplementary Table). Where statistically significant between-group differences were reported, single RCT evidence indicated that: sexual satisfaction was significantly greater with a PDE5i compared with placebo, [23;24] as was ejaculatory control and ejaculatory confidence [23]; there were no statistically significant differences between PDE5is and SSRIs on PE Grade scores, [15;16] or IIEF [27]; whilst for PDE5is combined with an SSRI in comparison with an SSRI alone there was a significantly greater increase in the combined 
therapy group in intercourse satisfaction [19;25]; control over ejaculation, sexual act time and interpersonal difficulty related to ejaculation[20] and intercourse frequency [19]. (Table 2) Sexual satisfaction was also significantly better with sildenafil compared with lidocaine gel, or tramadol[24]; and patient and partner sexual satisfaction was significantly better with sildenafil combined with behavioural therapy than behavioural therapy alone.[18] (Table 2).

\subsection{Safety outcomes}

Limitations in the reporting of adverse events did not permit a meta-analysis for this outcome (Supplementary Table). Single RCT evidence suggests that sildenafil and tadalafil and are associated with a greater incidence of flushing and headache compared with placebo [21-23] and tadalafil is also associated with a greater incidence of palpitations.[22;23] (Table 2). Single RCT evidence also suggests that whilst differing in the type of some adverse events, both PDE5is and SSRIs are associated with adverse events (Table 2). Single RCT evidence for PDE5is combined with an SSRI compared with SSRI alone also suggests that whilst differing in the type of some adverse events, both combination therapy and monotherapy are associated with adverse events; with more headache and flushing reported for: sildenafil plus fluoxetine compared with fluoxetine[25] and sildenafil plus sertraline compared with sertraline[17;19] (Table 2).

\section{Discussion}

Pooled evidence suggests that PDE5is are significantly more effective than placebo at increasing IELT over four to 12 weeks. The two RCTs that evaluated sildenafil excluded men with erectile dysfunction defined as an International Index of Erectile Function score $<22[23 ; 24]$ However, one of these RCTs reported that some of the patients enrolled may have had mild comorbid erectile dysfunction.[23] One of the placebo-controlled RCTs was described as single-blind, which may have contributed to selection bias[24]. Allocation concealment was not reported by two of the RCTs, which may have also contributed to selection bias.[23;24] Blinded outcome assessment was also not reported by these two RCTs, which may have contributed to detection bias. Due to the clinical and observed statistical heterogeneity coupled with the limited methodological quality across RCTs, these results should be interpreted with caution.

Sexual satisfaction, ejaculatory control and ejaculatory confidence appear significantly better with PDE5i than placebo. However, more adverse events including headache and flushing appear to be reported with PDE5is compared with placebo.

Pooled evidence suggests that there is no statistically significant difference in IELT between PDE5is and SSRIs over four to 24 weeks. However, a high level of statistically significant between-trial heterogeneity is evident. Across these RCTs, where reported the administration of the PDE5i was 30 minutes, [15] one hour, [16;24] two hours,[27] or one to three hours pre-coitus;[27] two reporting that the time of administration was the same in both treatment groups (two hours). [27] In terms of the SSRI comparator, one RCT reported that sertraline was prescribed four hours prior to sexual intercourse[15], whilst one RCT did not report the time of sertraline administration[18]. Paroxetine was prescribed two hours before intercourse [27], four hours before intercourse,[24] or daily [16]. Fluoxetine was 
prescribed 90mg once per week. [22] The half-lives of fluoxetine, paroxetine and sertraline range from 16 to 96 hours[30]. SSRIs such as these are absorbed relatively slowly, but completely, by the gut (time to peak plasma concentration is 4 to 6 hours)[31]. Current recommendations for SSRIs in the treatment of PE include dapoxetine on-demand (the only approved SSRI for treatment of PE) or other off-label daily SSRIs that are not amenable to on-demand.[32] The variability across the included RCTs in the present review in terms of dosage and time of administration of the SSRI comparator may account for some of the observed heterogeneity in IELT.

No significant between-group differences are evident on either the PE Grade or the IIEF for PDE5is compared with SSRIs. Adverse events are reported with both PDE5is (e.g., headache, palpitations and flushing) and SSRIs (e.g., somnolence, headache and nausea).

Pooled evidence across six RCTs suggests that combination therapy comprising PDE5i plus an SSRI is significantly more effective at increasing IELT over eight to 16 weeks compared with an SSRI alone. However, a high level of statistically significant between-trial heterogeneity is evident. Across the RCTs included in this meta-analysis, the IELT results were diverse. There was no statistically significant difference in IELT between tadalafil or tadalafil combined with fluoxetine taken weekly and fluoxetine weekly alone[22] Similarly, there was no significant difference on IELT from one RCT between mirodenafil combined with dapoxetine on-demand and dapoxetine alone[20]. However, sildenafil combined with sertraline daily was significantly more effective at increasing IELT when compared with sertraline daily alone in men with both lifelong[19] and acquired PE[17]. Whilst there was no significant difference in IELT between tadalafil and paroxetine on-demand from one RCT (100 participants), evidence from the same RCT also suggests that tadalafil combined with paroxetine on-demand is significantly more effective on IELT than tadalafil alone [27]. In the RCT by Polat et al. [27] the study authors reported that they did not use a stopwatch to measure IELT in order to avoid any decrease in the quality of sexual intercourse. They also compared their observations with those of a prospective study evaluating combination therapy of sildenafil and paroxetine on-demand on IELT[33], noting that the study reported a significant improvement in IELT in patients using combined therapy and that the patients under combined therapy reported significantly greater intercourse satisfaction than those receiving paroxetine alone. However, Polat et al. [27] did not report on ejaculatory control or sexual satisfaction, noting this as a study limitation. IELT is reported to have a significant direct effect on perceived control over ejaculation, but not a significant direct effect on ejaculation-related personal distress or satisfaction with sexual intercourse [34].

Intercourse satisfaction and frequency; control over ejaculation, sexual act time and interpersonal difficulty appear significantly better with PDE5is combined with an SSRI compared with SSRI alone. Adverse events are reported with both PDE5 inhibitors combined with an SSRI and SSRI alone, with more headache and flushing associated with PDE5 inhibitors combined with an SSRI.

Single RCT evidence suggests sildenafil is significantly more effective than the squeeze technique at increasing IELT[16] and that sildenafil combined with behavioural therapy is significantly more effective than behavioural therapy alone.[18] Single RCT evidence also 
suggests that both lidocaine gel and tramadol on-demand are both significantly more effective than sildenafil at increasing IELT.[24] However, the same RCT reported that the greatest improvement in sexual satisfaction was with sildenafil, which was significantly better than paroxetine or lidocaine gel.

The risk of bias assessment undertaken for this review indicates the majority of RCTs evaluating PDE5is in the treatment of PE are of unclear risk of detection bias, mainly due to limited reporting regarding blinding of the outcome assessment. Key aspects of best practice in RCT design to minimise bias include a robust randomisation method, concealment of treatment group allocation, and, where possible, blinding of participants and trial personnel, and blinded outcome assessment; all of which should be clearly stated in the RCT report [35]. The unclear methodological quality of the current evidence base for PDE5is in the treatment of PE, coupled with the limited reporting by some RCTs of the presence or otherwise of erectile dysfunction [14;19;26] supports existing concerns regarding limited well-designed studies that evaluate the use of PDE5is in PE patients without erectile dysfunction.[36]

The strengths of the present review are that it was undertaken to high methodological standards.[37] Several electronic database sources were searched for evidence. RCT evidence for mirodenafil, sildenafil, tadalafil, and vardenafil in the management of PE were identified. No RCT evidence for avanafil or udenafil in PE was identified. Study selection and data extraction was undertaken by two reviewers. Methodological quality of included studies was assessed. A meta-analysis was presented. Limitations include the following. Theses and dissertations were not included and non-English publications were not fully translated (only the English language abstract was used). Although our database search strategy was comprehensive, the possibility of a publication bias cannot be discounted. Insufficient numbers of RCT comparisons were available for any meaningful assessment of funnel plot symmetry to be undertaken.

In the review by Asimakopoulos et al. (2012),[5] which included a meta-analysis for PDE5is compared with placebo and a meta-analysis of PDE5is combined with an SSRI compared with SSRI alone, the authors pooled IELT effect estimates across studies using a standardised mean difference. However, the method assumes that the differences in standard deviations among studies reflect differences in measurement scales and not real differences in variability among study populations.[38] The present review has presented a mean difference meta-analysis. Asimakopoulos et al. (2012),[5] pooled data across different study types (non-randomised studies, laboratory ejaculatory latency time studies and RCTs) in the same meta-analysis. The present review has meta-analysed only RCT evidence, including six additional RCTs[14;17;20;24;26;27] to those included in the Asimakopoulos et al. (2012) review [5]. The present review also presents a meta-analysis of IELT for PDE5is compared with SSRIs and summarises the RCT evidence for PDE5is compared with topical anaesthetics, tramadol and behavioural therapy.

All mean IELT data used in the present review were those reported in the original RCT article. Only one RCT reported IELT as a geometric mean (data not pooled with other RCTs).[28] A positively skewed IELT distribution may overestimate treatment effects if the 
mean IELT, instead of the geometric mean IELT, is reported.[39] As such, the IELT outcomes in the present review should be interpreted with caution.

It is difficult to quantify how acceptable and meaningful the changes in IELT are for men with PE, without being able to evaluate the relationship between IELT, ejaculation control, and sexual satisfaction from the current RCT evidence. IELT is reported to have a significant direct effect on perceived control over ejaculation, but not a significant direct effect on ejaculation-related personal distress or satisfaction with sexual intercourse [34]. There is currently no published literature which identifies a clinically significant threshold for IELT response to any intervention [40]. PDE5is might offer an acceptable treatment option for men with PE both as a means of a second attempt at intercourse and in terms of the adverse event profile compared with other pharmacological agents. However, the reporting of adverse events across the current evidence is disparate often with only selected adverse events reported or numbers of participants experiencing adverse events not reported by group which restricts statistical pooling across RCTs. Furthermore, interaction effects between PDE5is and SSRIs are not presently evaluated in the RCT evidence base. Patient acceptability or persistence with treatment are also not evaluated in the current RCT evidence base.

\section{Conclusions}

The present systematic review has evaluated the safety and efficacy of PDE5is in the treatment of premature ejaculation. The possible mechanisms of the action of PDE5is, along with long-lasting effects and age-dependent efficacy were outside of the scope for the review as was change in erectile function. Pooled RCT evidence suggests that PDE5is are significantly more effective than placebo and that PDE5is combined with an SSRI are significantly more effective than SSRI alone at increasing IELT in men with PE. Increases in IELT are not significantly different between PDE5is compared with SSRIs. However, these findings should be interpreted with caution given the high levels of statistically heterogeneity that are evident across RCTs and the clinical heterogeneity of recruited participants along with the unclear methodological quality of the existing RCT evidence base. Furthermore, a potential bias in the evaluation of any interventions for treating PE is the effect of the relationship between clinician and patient. Single RCT evidence suggests a PDE5i is significantly better than squeeze technique, but that both lidocaine gel and tramadol are significantly better than a PDE5i on IELT. Single RCT evidence also suggests that a PDE5i combined with behavioural therapy is better on IELT than behavioural therapy alone. We found no RCT evidence comparing PDE5is directly with psychotherapeutic techniques. Other efficacy outcomes including sexual satisfaction and ejaculatory control appear better with PDE5is compared with placebo and with PDE5is combined with an SSRI compared with an SSRI alone. Adverse events are reported with both PDE5is and with SSRIs.

Further RCTs should be better reported in line with the CONSORT statement,[35] and should report on patient acceptability of PDE5is along with clearer reporting on adverse events in order to permit future pooling of data across RCTs. Future studies should also evaluate the relationship between changes in IELT and other efficacy outcomes including 
sexual satisfaction and ejaculatory control. Long term follow-up of safety and efficacy outcomes and persistence with treatment are also warranted along with effects of treatment discontinuation

\section{Supplementary Material}

Refer to Web version on PubMed Central for supplementary material.

\section{Acknowledgements}

This work was funded by NIHR Evaluation, Trials and Studies Coordinating Centre (NETSCC).

\section{References}

1. McMahon CG, Althof S, Waldinger MD, Porst H, Dean J, Sharlip I, Adaikan PG, Becher E, Broderick GA, Buvat J, Dabees K, et al. An evidence-based definition of lifelong premature ejaculation: report of the International Society for Sexual Medicine Ad Hoc Committee for the Definition of Premature Ejaculation. BJU Int. 2008; 102:338-350. [PubMed: 18498422]

2. Godpodinoff ML. Premature ejaculation: clinical subgroups and etiology. J Sex Marital Ther. 1989; 15:130-134. [PubMed: 2769774]

3. Serefoglu EC, McMahon CG, Waldinger MD, Althof SE, Shindel A, Adaikan G, Becher EF, Dean J, Giuliano F, Hellstrom WJG, Giraldi A, et al. An Evidence-Based Unified Definition of Lifelong and Acquired Premature Ejaculation: Report of the Second International Society for Sexual Medicine Ad Hoc Committee for the Definition of Premature Ejaculation. Sexual Medicine. 2014; 2:41-59. [PubMed: 25356301]

4. Richardson D, Goldmeier D, Green J, Lamba H, Harris JRW. Recommendations for the management of premature ejaculation: BASHH Special Interest Group for Sexual Dysfunction. International Journal of STD and AIDS. 2006; 17:1-6.

5. Asimakopoulos AD, Miano R, Finazzi Agro E, Vespasiani G, Spera E. Does current scientific and clinical evidence support the use of phosphodiesterase type 5 inhibitors for the treatment of premature ejaculation? a systematic review and meta-analysis. J Sex Med. 2012; 9:2404-2416. [PubMed: 22248110]

6. Aversa A, Francomano D, Bruzziches R, Natali M, Spera G, Lenzi A. Is there a role for phosphodiesterase type-5 inhibitors in the treatment of premature ejaculation? Int J Impot Res. 2011; 23:17-23. [PubMed: 21270821]

7. Burton TD, Liday C. The comparison of combination SSRI and PDE-5 inhibitor therapy to SSRI monotherapy in men with premature ejaculation. Ann Pharmacother. 2011; 45:1000-1004. [PubMed: 21775693]

8. Chen J, Keren-Paz G, Bar-Yosef Y, Matzkin H. The Role of Phosphodiesterase Type 5 Inhibitors in the Management of Premature Ejaculation: A Critical Analysis of Basic Science and Clinical Data. Eur Urol. 2007; 52:1331-1339. [PubMed: 17728050]

9. McMahon CG, McMahon CN, Leow LJ, Winestock CG. Efficacy of type-5 phosphodiesterase inhibitors in the drug treatment of premature ejaculation: a systematic review. BJU Int. 2006; 98:259-272. [PubMed: 16879663]

10. Cooper K, Martyn-St James M, Kaltenthaler E, Dickinson K, Cantrell A. Interventions to treat premature ejaculation: a systematic review short report. Health Technology Assessment. 2015; 19:1-180.

11. Higgins, JPT., Altman, DG., Sterne, JAC., on behalf of the Cochrane Statistical Methods Group and the Cochrane Bias Methods Group. Assessing risk of bias in included studies. Cochrane Handbook for Systematic Reviews of Interventions Version 5.1.0 (updated March 2011). Higgins, JPT., GS, editors. The Cochrane Collaboration; 2011. Available from www.cochranehandbook.org [Accessed 4 January 2016] 
12. The Nordic Cochrane Centre TCC. The Cochrane Collaboration Review Manager (RevMan). [5.2]. 2012 [Accessed 4 January 2016]

13. Higgins JPTH, Thompson SG, Deeks JJ, Altman DG. Measuring inconsistency in meta-analyses. BMJ. 2003; 327:557-560. [PubMed: 12958120]

14. Culha M, Ozkan L, Ozkurkcugil C, Gokalp A. Comparison of fluoxetine vs. fluoxetine plus tadalafil in the treatment of premature ejaculation - a double blind, placebo control study. J Sex Med. 2008; 5:60-61. [PubMed: 17645447]

15. Mathers MJ, Klotz T, Roth S, Lummen G, Sommer F. Safety and efficacy of vardenafil versus sertraline in the treatment of premature ejaculation: a randomised, prospective and crossover study. Andrologia. 2009; 41:169-175. [PubMed: 19400851]

16. Wang WF, Wang Y, Minhas S, Ralph DJ. Can sildenafil treat primary premature ejaculation? A prospective clinical study. Int J Urol. 2007; 14:331-335. [PubMed: 17470165]

17. Zhang X, Tang D, Yang J, Shi K, Goa J, Hao Z, Zhou J, Liang C. Combination of Sertraline and Sildenafil versus Sertraline Monotherapy in the Treatment of Acquired Premature Ejaculation without Concomitant Diseases. Andrology. 2014

18. Tang W, Ma L, Zhao L, Liu Y. Efficacy and safety of sertraline, viagra and cardura in patients with premature ejaculation. Chinese Journal of Andrology. 2004; 18:20-2. 25.

19. Zhang XS, Wang YX, Huang XY, Leng J, Li Z, Han YF. Comparison between sildenafil plus sertraline and sertraline alone in the treatment of premature ejaculation. Zhonghua Nan Ke Xue. 2005; 11:520-525. [PubMed: 16078671]

20. Lee WK, Cho ST, Lee YS, Oh CY, Yu CH, Cho JS, Lee SK, Yang DY. Comparison between ondemand dosing of dapoxetine alone and dapoxetine plus mirodenafil in patients with premature ejaculation; prospective, randomized, doubleblind, and placebo-controlled. J Sex Med. 2012; 9:203-204.

21. Atan A, Basar MM, Tuncel A, Ferhat M, Agras K, Tekdogan U. Comparison of efficacy of sildenafil-only, sildenafil plus topical EMLA cream, and topical EMLA-cream-only in treatment of premature ejaculation. Urology. 2006; 67:388-391. [PubMed: 16461091]

22. Mattos RM, Marmo Lucon A, Srougi M. Tadalafil and fluoxetine in premature ejaculation: prospective, randomized, double-blind, placebo-controlled study. Urol Int. 2008; 80:162-165. [PubMed: 18362486]

23. McMahon CG, Stuckey BGA, Andersen M, Purvis K, Koppiker N, Haughie S, Boolell M. Efficacy of sildenafil citrate (Viagra) in men with premature ejaculation. J Sex Med. 2005; 2:368-375. [PubMed: 16422868]

24. Gameel TA, Tawfik AM, Abou-Farha MO, Bastawisy MG, El-Bendary MA, El-Gamasy AE-N. On-demand use of tramadol, sildenafil, paroxetine and local anaesthetics for the management of premature ejaculation: A randomised placebo-controlled clinical trial. Arab J Urol. 2013; 11:392397. [PubMed: 26558110]

25. Hosseini MM, Yarmohammadi H. Effect of fluoxetine alone and in combination with sildenafil in patients with premature ejaculation. Urol Int. 2007; 79:28-32. [PubMed: 17627164]

26. Mokhtari G, Damavand RS, Khosropanah I, Roushani A, Kazemnezhad E, Esmaeili S, Baghani H, Motiee R. The efficacy and safety of combination therapy with tadalafil and serteraline in lifelong premature ejaculation: A randomized double blind study using a validated questionnaire. International Journal of Urology. 2014; 21:A274. 2014.

27. Polat EC, Ozbek E, Otunctemur A, Ozcan L, Simsek A. Combination therapy with selective serotonin reuptake inhibitors and phosphodiesterase- 5 inhibitors in the treatment of premature ejaculation. Andrologia. 2014 n/a.

28. Aversa A, Pili M, Francomano D, Bruzziches R, Spera E, La Pera G, Spera G. Effects of vardenafil administration on intravaginal ejaculatory latency time in men with lifelong premature ejaculation. Int J Impot Res. 2009; 21:221-227. [PubMed: 19474796]

29. European Medicines Agency. Questions and answers on Priligy (dapoxetine, $30 \mathrm{mg}$ and $60 \mathrm{mg}$ tablets). Outcome of a procedure under Article 29 of Directive 2001/83/EC as amended. European Medicines Agency. Jan 20.2012 [20-1-20128-7-2013] EMA/CHMP/842278/2011 Rev. 1. EMEA/H/A-29/1294. 
30. Hiemke C, Härtter S. Pharmacokinetics of selective serotonin reuptake inhibitors. Pharmacology \& Therapeutics. 2000; 85:11-28. [PubMed: 10674711]

31. van Harten J. Clinical Pharmacokinetics of Selective Serotonin Reuptake Inhibitors. Clin Pharmacokinet. 1993; 24:203-220. [PubMed: 8384945]

32. Hatzimouratidis K, Eardley I, Giuliano F, Hatzichristou D, Moncada I, Salonia A, Vardi Y, Wespes E. Guidelines on Male Sexual Dysfunction: Erectile dysfunction and premature ejaculation. European Association of Urology. 2015 European Association of Urology.

33. Salonia A, Maga T, Colombo R, Scattoni V, Briganti A, Cestari A, Guazzoni G, Rigatti P, Montorsi F. A prospective study comparing paroxetine alone versus paroxetine plus sildenafil in patients with premature ejaculation. The Journal of urology. 2002; 168:2486-2489. [PubMed: 12441946]

34. Patrick DL, Rowland D, Rothman M. Interrelationships among measures of premature ejaculation: the central role of perceived control. The journal of sexual medicine. 2007; 4:780-788. [PubMed: 17419817]

35. Schulz KF, Altman DG, Moher D. CONSORT 2010 Statement: updated guidelines for reporting parallel group randomised trials. BMJ. 2010; 340:c322.

36. Jannini EA, McMahon C, Chen J, Aversa A, Perelman M. The controversial role of phosphodiesterase type 5 inhibitors in the treatment of premature ejaculation. J Sex Med. 2011; 8:2135-2143. [PubMed: 21791006]

37. Moher D, Liberati A, Tetzlaff J, Altman DG, The PRISMA Group. Preferred Reporting Items for Systematic Reviews and Meta-Analyses: The PRISMA Statement. PLoS Med. 2009; 6:e1000097. [PubMed: 19621072]

38. Deeks, JJ., Higgins, JPT., Altman, DG., on behalf of the Cochrane Statistical Methods Group. Chapter 9: Analysing data and undertaking meta-analyses. Cochrane Handbook for Systematic Reviews of Interventions Version 5.1.0 [updated March 2011]. Higgins, JPT., Green, S., editors. The Cochrane Collaboration; 2011. Available from www.cochrane-handbook.org [Accessed 4 January 2016]

39. Waldinger MD, Zwinderman AH, Olivier B, Schweitzer DH. Geometric mean IELT and premature ejaculation: Appropriate statistics to avoid overestimation of treatment efficacy. Journal of Sexual Medicine. 2008; 5:492-499. 2008. [PubMed: 18179458]

40. McMahon CG. Clinical trial methodology in premature ejaculation observational, interventional, and treatment preference studies--part II--study design, outcome measures, data analysis, and reporting. J Sex Med. 2008; 5:1817-1833. [PubMed: 18507716] 


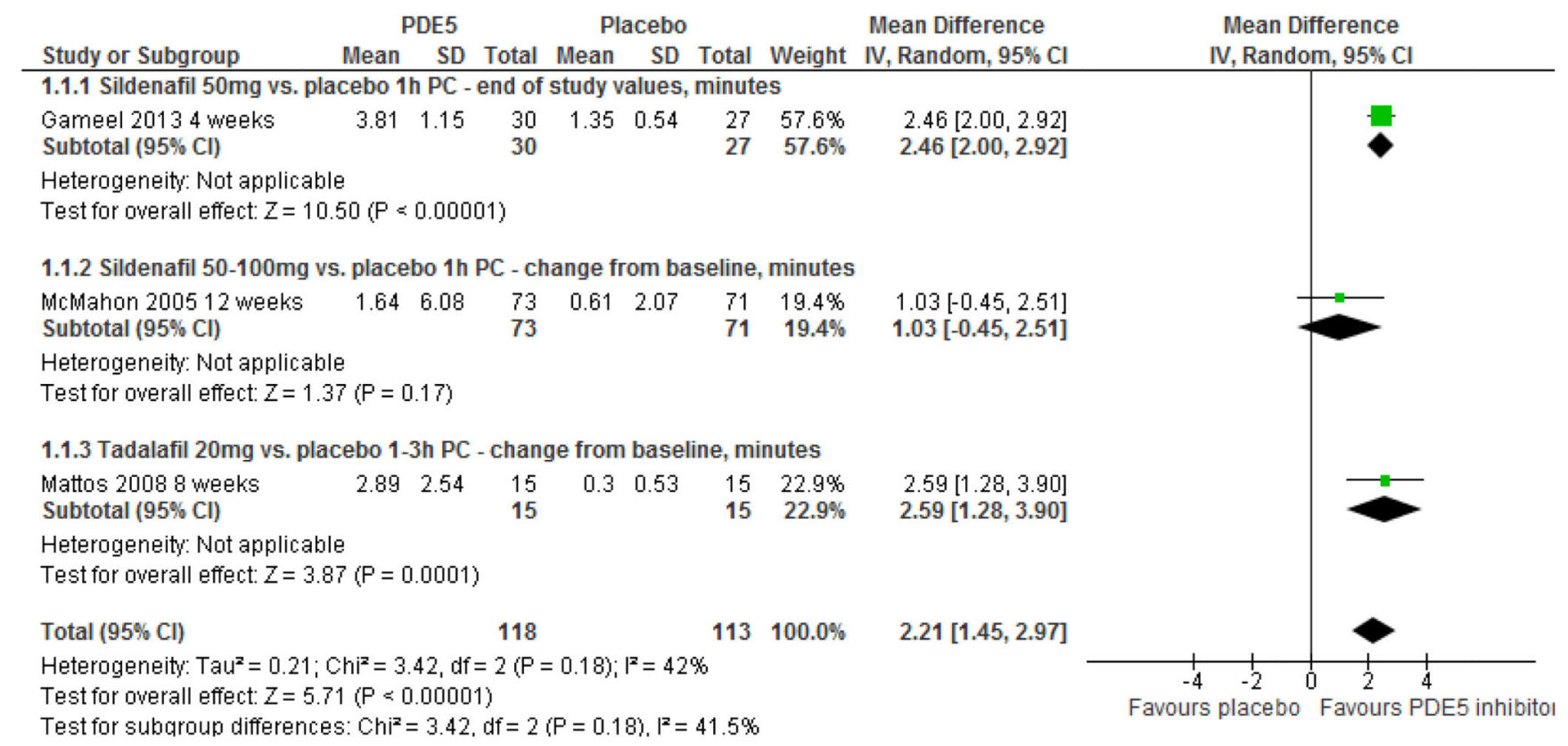

Figure 1. PDE5 inhibitors vs. placebo - forest plot of IELT outcomes PC, pre-coitus 


\begin{tabular}{|c|c|c|c|c|c|c|c|c|c|}
\hline Study or Subgroup & \multicolumn{3}{|c|}{ PDE5 inhibitor } & \multicolumn{3}{|c|}{ SSRI } & \multicolumn{2}{|c|}{ Mean Difference } & $\begin{array}{c}\text { Mean Difference } \\
\text { IV, Random, } 95 \% \mathrm{Cl}\end{array}$ \\
\hline \multicolumn{9}{|c|}{ 1.2.1 Sildenafil $50 \mathrm{mg}$ vs. sertraline dose NR - end of study } & \\
\hline $\begin{array}{l}\text { Tang } 20046 \text { weeks } \\
\text { Subtotal }(95 \% \mathrm{Cl})\end{array}$ & 3.63 & 0.55 & $\begin{array}{l}30 \\
30\end{array}$ & 4.85 & 0.57 & $\begin{array}{l}30 \\
30\end{array}$ & $\begin{array}{l}19.0 \% \\
19.0 \%\end{array}$ & $\begin{array}{l}-1.22[-1.50,-0.94] \\
-1.22[-1.50,-0.94]\end{array}$ & 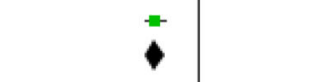 \\
\hline \multicolumn{10}{|c|}{$\begin{array}{l}\text { Heterogeneity: Not applicable } \\
\text { Test for overall effect: } Z=8.44 \text { ( } P=0.00001)\end{array}$} \\
\hline \multicolumn{10}{|c|}{ 1.2.2 Sildenafil $50 \mathrm{mg} 1 \mathrm{~h}$ vs. paroxetine $20 \mathrm{mg} 4 \mathrm{~h} \mathrm{PC}$ - end of study values, minutes } \\
\hline $\begin{array}{l}\text { Gameel } 20134 \text { weeks } \\
\text { Subtotal }(95 \% \mathrm{Cl})\end{array}$ & 3.81 & 1.15 & $\begin{array}{l}30 \\
30\end{array}$ & 3.11 & 1.08 & $\begin{array}{l}28 \\
28\end{array}$ & $\begin{array}{l}18.1 \% \\
\mathbf{1 8 . 1 \%}\end{array}$ & $\begin{array}{c}0.70[0.13,1.27] \\
0.70[0.13,1.27]\end{array}$ & \\
\hline \multicolumn{10}{|c|}{$\begin{array}{l}\text { Heterogeneity: Not applicable } \\
\text { Test for overall effect: } Z=2.39(P=0.02)\end{array}$} \\
\hline \multicolumn{10}{|c|}{ 1.2.3 Sildenafil $50 \mathrm{mg} 1 \mathrm{~h}$ PC vs. paroxetine $20 \mathrm{mg} / \mathrm{d}$ - change from baseline, minutes } \\
\hline $\begin{array}{l}\text { Wang } 200724 \text { weeks } \\
\text { Subtotal }(95 \% \mathrm{Cl})\end{array}$ & 5.12 & 1.54 & $\begin{array}{l}59 \\
59\end{array}$ & 3.86 & 0.88 & $\begin{array}{l}49 \\
49\end{array}$ & $\begin{array}{r}18.5 \% \\
\mathbf{1 8 . 5 \%}\end{array}$ & $\begin{array}{r}1.26[0.80,1.72] \\
1.26[0.80,1.72]\end{array}$ & \\
\hline \multicolumn{10}{|c|}{$\begin{array}{l}\text { Heterogeneity: Not applicable } \\
\text { Test for overall effect: } Z=5.32(P \leq 0.00001)\end{array}$} \\
\hline \multicolumn{10}{|c|}{ 1.2.4 Tadalafil $20 \mathrm{mg} 1-3 \mathrm{~h}$ PC vs. fluoxetine $90 \mathrm{mg} / \mathrm{w}$ - change from baseline, minutes } \\
\hline $\begin{array}{l}\text { Mattos } 20088 \text { weeks } \\
\text { Subtotal }(95 \% \mathrm{Cl})\end{array}$ & 2.89 & 2.54 & $\begin{array}{l}15 \\
15\end{array}$ & 2.95 & 1.52 & $\begin{array}{l}15 \\
15\end{array}$ & $\begin{array}{l}13.2 \% \\
13.2 \%\end{array}$ & $\begin{array}{l}-0.06[-1.56,1.44] \\
-0.06[-1.56,1.44]\end{array}$ & \\
\hline \multicolumn{10}{|c|}{$\begin{array}{l}\text { Heterogeneity: Not applicable } \\
\text { Test for overall effect: } Z=0.08(P=0.94)\end{array}$} \\
\hline \multicolumn{10}{|c|}{ 1.2.5 Tadalafil $20 \mathrm{mg}$ vs. paroxetine $20 \mathrm{mg} 2 \mathrm{~h} \mathrm{PC}$ - end of study values, minutes } \\
\hline $\begin{array}{l}\text { Polat } 201412 \text { weeks } \\
\text { Subtotal }(95 \% \mathrm{Cl})\end{array}$ & 1.84 & 0.62 & $\begin{array}{l}50 \\
50\end{array}$ & 1.96 & 1.12 & $\begin{array}{l}50 \\
50\end{array}$ & $\begin{array}{l}18.8 \% \\
18.8 \%\end{array}$ & $\begin{array}{l}-0.12[-0.47,0.23] \\
-0.12[-0.47,0.23]\end{array}$ & \\
\hline \multicolumn{10}{|c|}{$\begin{array}{l}\text { Heterogeneity: Not applicable } \\
\text { Test for overall effect: } Z=0.66(P=0.51)\end{array}$} \\
\hline \multicolumn{10}{|c|}{ 1.2.6 Vardenafil $10 \mathrm{mg} 30 \mathrm{~min}$ vs. sertraline $50 \mathrm{mg} 4 \mathrm{~h} \mathrm{PC}$ - end of study values, minutes } \\
\hline $\begin{array}{l}\text { Wathers } 20096 \text { week } \\
\text { Subtotal }(95 \% \mathrm{Cl})\end{array}$ & 5.01 & 3.69 & $\begin{array}{l}26 \\
26\end{array}$ & 3.12 & 1.89 & $\begin{array}{l}23 \\
23\end{array}$ & $\begin{array}{l}12.5 \% \\
12.5 \%\end{array}$ & $\begin{array}{r}1.89[0.27,3.51] \\
1.89[0.27,3.51]\end{array}$ & \\
\hline \multicolumn{10}{|c|}{$\begin{array}{l}\text { Heterogeneity: Not applicable } \\
\text { Test for overall effect: } Z=2.29(P=0.02)\end{array}$} \\
\hline Total $(95 \% \mathrm{Cl})$ & & & 210 & & & 195 & $100.0 \%$ & $0.33[-0.63,1.30]$ & \\
\hline $\begin{array}{l}\text { Heterogeneity: } \operatorname{Tau}^{2}=1 \\
\text { Test for overall effect: } Z\end{array}$ & $\begin{array}{l}6 ; \mathrm{Chi}^{2} \\
0.68(\mathrm{P}\end{array}$ & $\begin{array}{l}=103.5 \\
=0.50\end{array}$ & $5, \mathrm{df}=$ & $5(\mathrm{P} \leq 0$ & 1.00001 & 1); $I^{2}=9$ & $95 \%$ & & $\begin{array}{cccc} & 1 & 1 & 1 \\
-4 & -2 & 0 & 2 \\
\text { Favours SSRI } & \text { Favours }\end{array}$ \\
\hline
\end{tabular}

Figure 2. PDE5 inhibitors vs. SSRIs - forest plot of IELT outcomes 


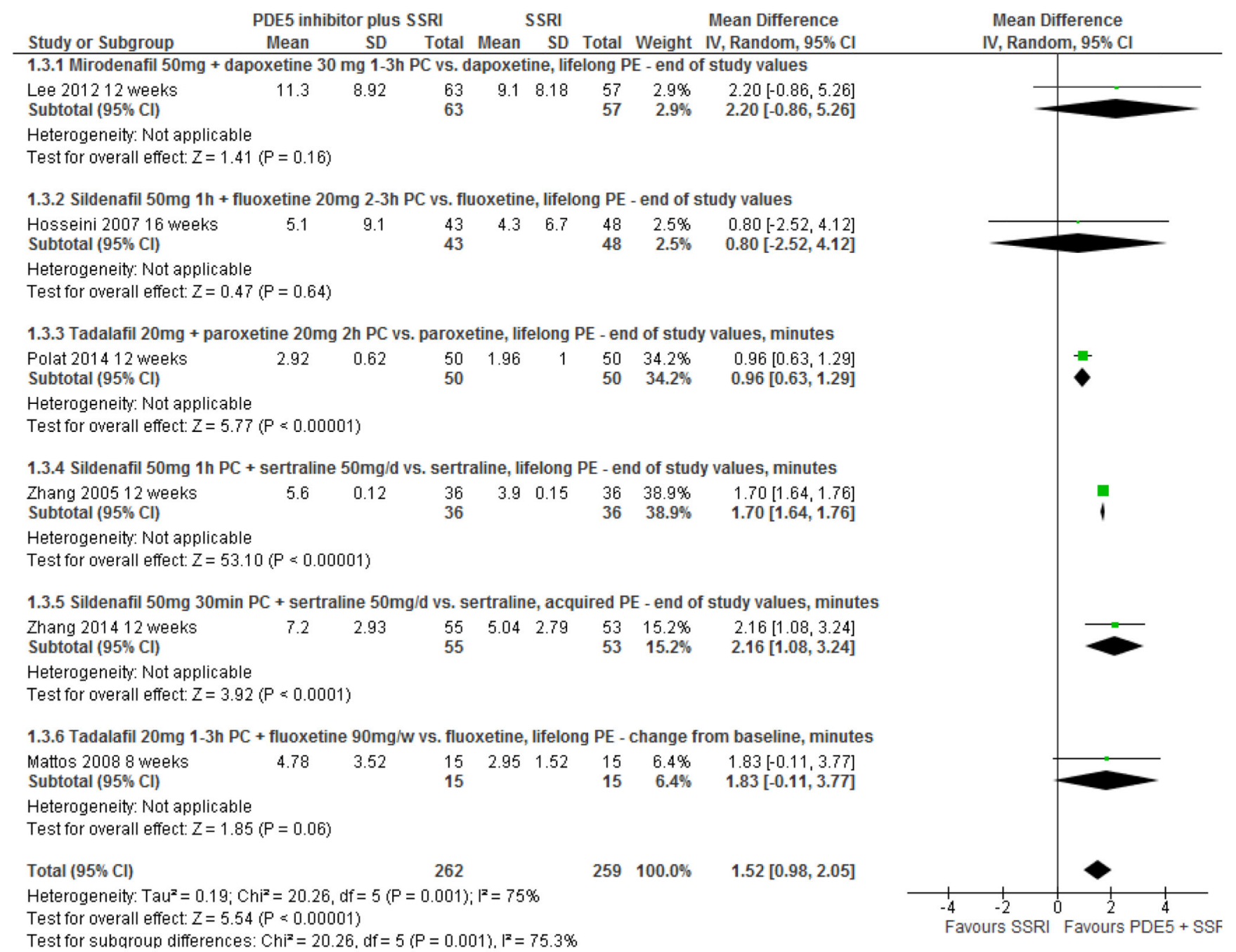

Figure 3. PDE5 inhibitors plus SSRIs vs. SSRIs - forest plot of IELT outcomes 


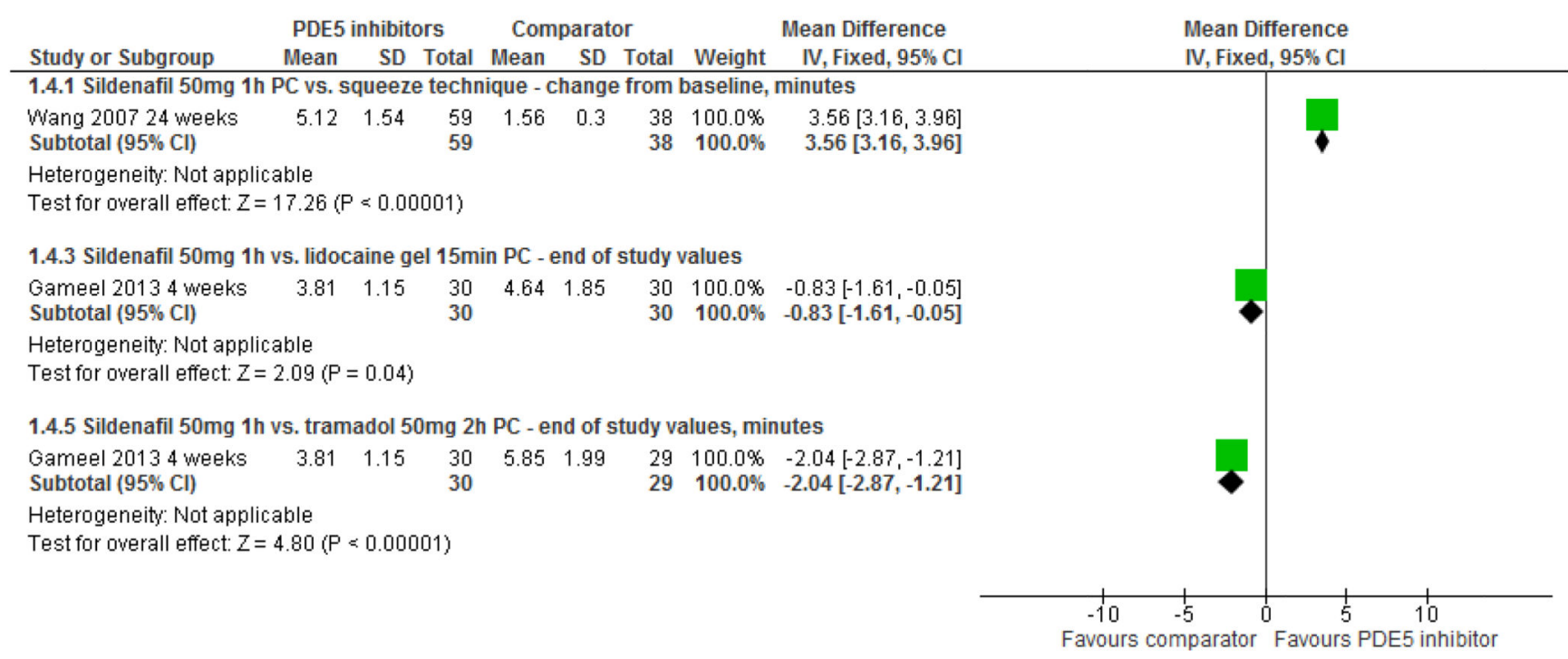

Figure 4. PDE5 inhibitors vs. squeeze technique, lidocaine gel or tramadol - forest plot of IELT outcomes 


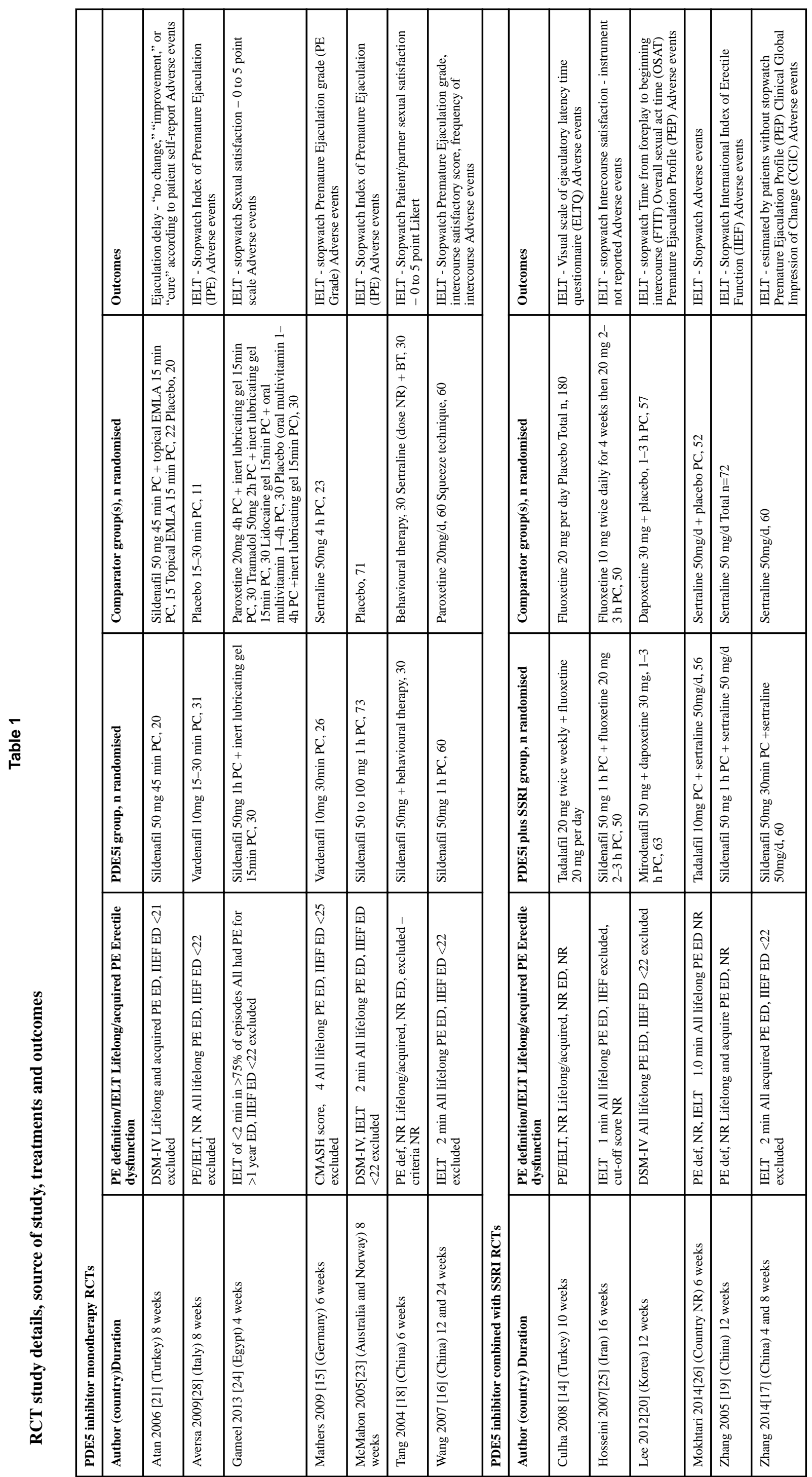




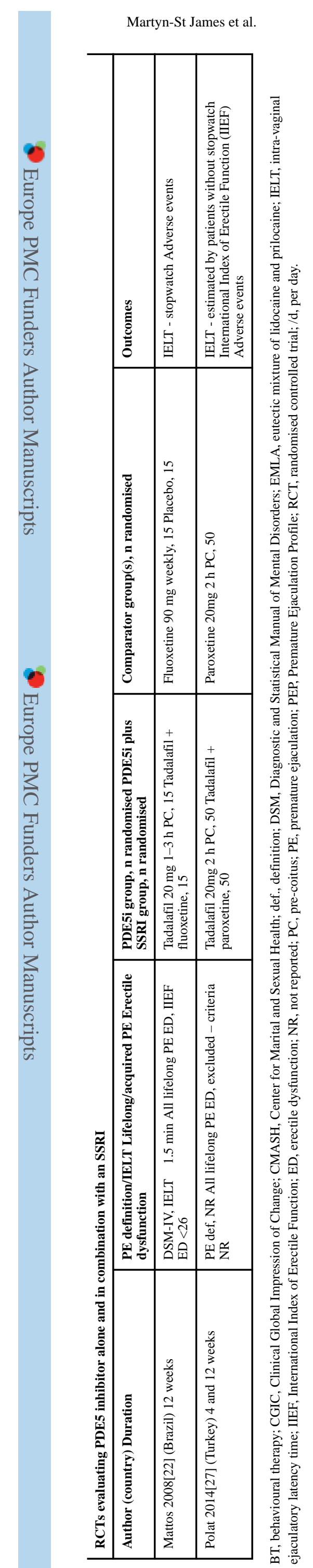

Page 18 


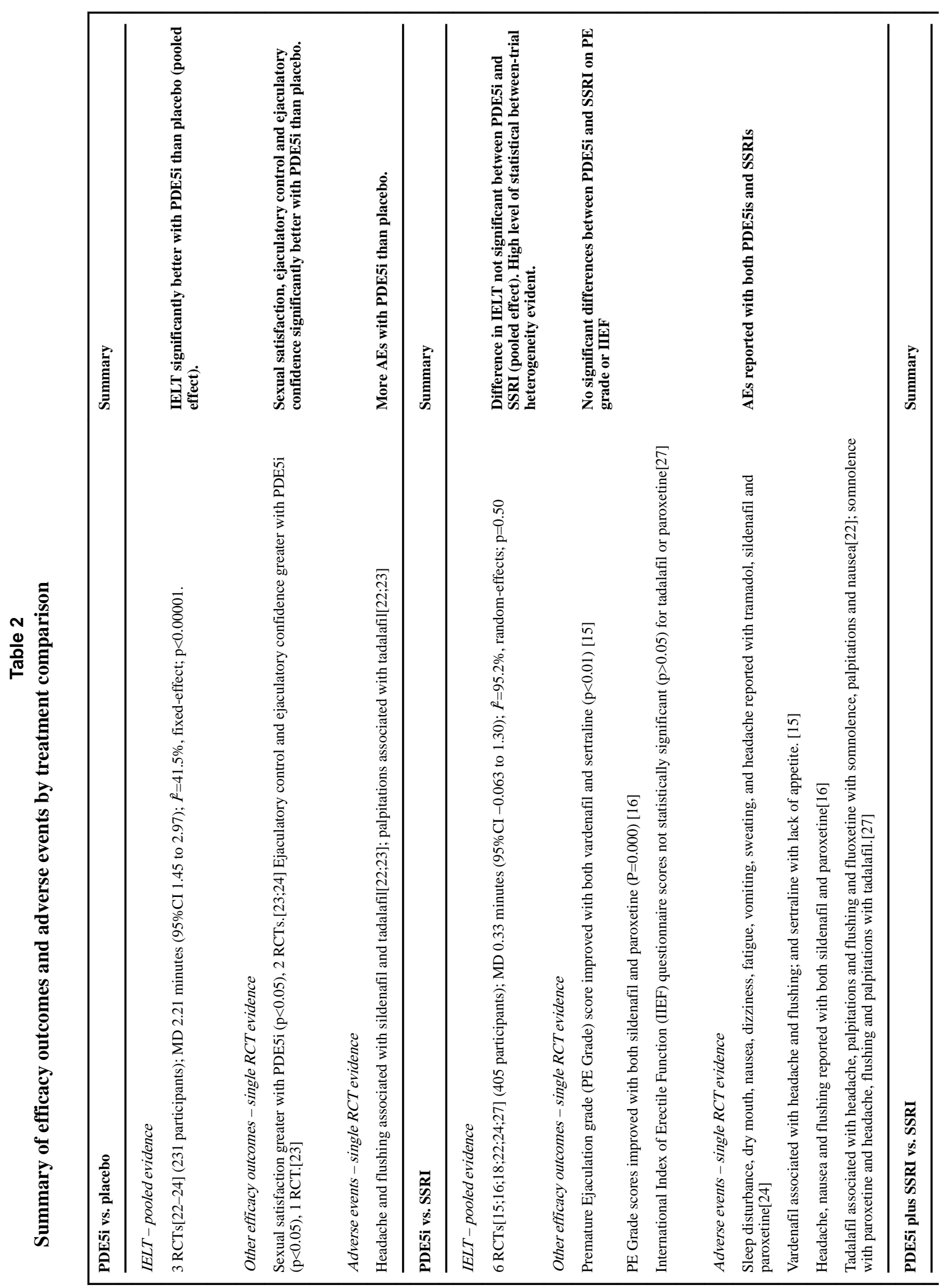

Eur Urol Focus. Author manuscript; available in PMC 2017 July 10. 


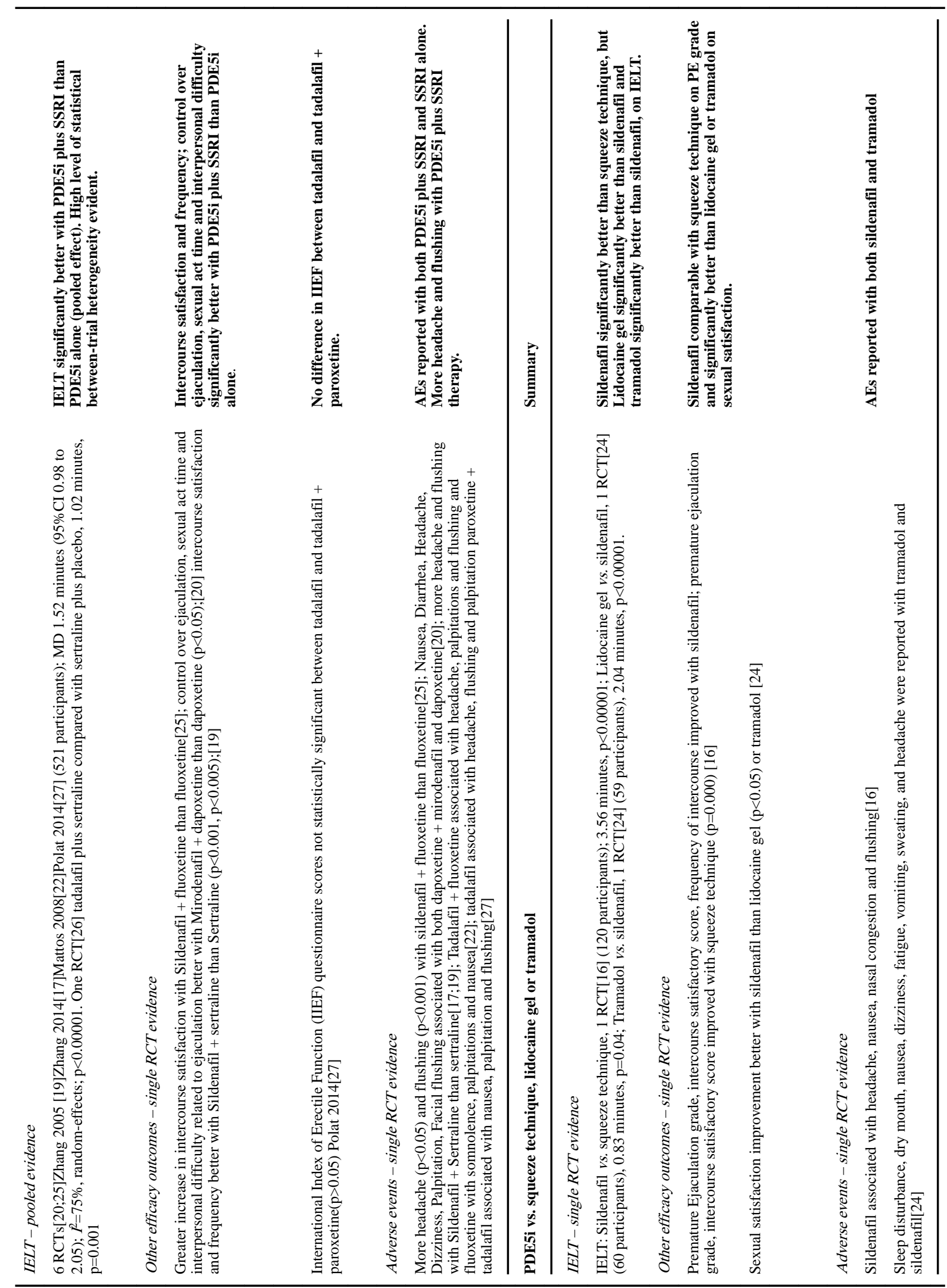

Eur Urol Focus. Author manuscript; available in PMC 2017 July 10. 


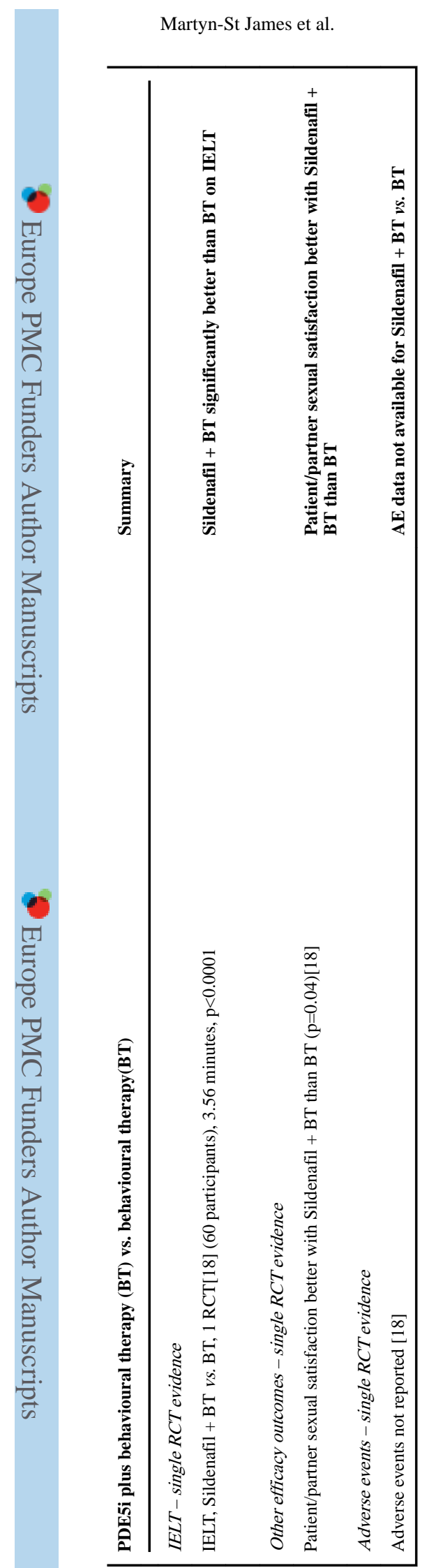

Page 21

Eur Urol Focus. Author manuscript; available in PMC 2017 July 10. 